\title{
The Value Of Mentoring To Develop Student Teachers' Work-Integrated Learning Skills
}

Prakash Singh, Nelson Mandela Metropolitan University, South Africa

Carmel Claire Mahomed, Nelson Mandela Metropolitan University, South Africa

\begin{abstract}
Mentors are expected to create an environment in which prospective employees can be trained to be productive and be able to excel when employed. The personal one-on-one mentoring is especially beneficial for potential employees, such as student teachers, to close the gap between theory they are exposed to at higher education institutions (HEIs) and teaching practice in schools. Motivated school mentors are expected to provide student teachers with work-integrated learning (WIL) skills of a high standard, particularly since these mentors are expected to be models of professionalism for the student teachers to emulate.
\end{abstract}

The aim of the study was to investigate whether the one-year Postgraduate Certificate in Education (PGCE) qualification at HEIs adequately develops the WIL skills of student teachers. Therefore, the objectives of the study were to ascertain the relationship between the theoretical knowledge provided by the PGCE curriculum and the development of WIL skills of student teachers in the schools and to determine the perceptions of school mentors of the PGCE to develop the WIL skills of student teachers. The target population for this quantitative study was school mentors of PGCE student teachers. Data were obtained by means of a structured questionnaire for the mentors. It was evident in this study that mentors were well-trained to develop the WIL skills of their protégés. The findings of this research, therefore, support the hypothesis that school mentors make a significant contribution to the development of the WIL skills of student teachers in the PGCE programme.

Keywords: Motivated School Mentors; Student Teachers' Work-Integrated Learning Skills; Initial Teacher Education Programmes; Human Resource Development

\section{INTRODUCTION}

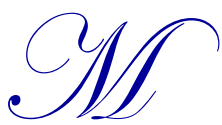

entoring can be a powerful human resource development and empowerment tool for the transmission of knowledge and skills in a supportive environment (Bilesanmi, 2011). It is a process in which mature and experienced staff serving as mentors share their wisdom, skills, knowledge, values and experiences with younger employees (or potential employees) on a one-on-one basis in order to develop the competencies of their mentees. Mentors are expected to create an environment in which prospective employees can be trained to be productive and be able to excel when employed. The personal one-on-one mentoring is especially beneficial for potential employees, such as student teachers, to close the gap between the theory they are exposed to at HEIs and teaching practice at schools. Motivated school mentors are expected to provide student teachers with WIL skills of a high standard, particularly since these mentors are expected to be models of professionalism for the student teachers to emulate.

Anderson and Shannon, as quoted by Abiddin and Hassan (2012), aptly define mentoring as:

A nurturing in which a more skilled or more experienced person, serving as a role model, teaches, sponsors, encourages, counsels, and befriends a less skilled or less experienced person for the purpose of promoting the 
latter's professional and/or personal development. Mentoring functions are carried out within the context of an ongoing, caring relationship between the mentor and the protégé. (p. 75)

A primary requirement of initial teacher education (ITE) is that it has to adhere to the academic rigour expected at universities where theoretical knowledge is largely the focus; but, at the same time, the student teachers are expected to ensure that the WIL skills that reflect the reality in the classrooms are attended to (DoE, 2007). This implies that student teachers are expected to have an in-depth understanding of the reality that prevails in the regular classrooms (Dungy, 2010; Stewart, 2011). Evidently, school mentors are the experienced teachers who serve as mentors to the PGCE student teachers during their internship. Chappuis, Chappuis and Stiggins (2009) believe that professional development works best "when it's on-site, job-embedded, sustained over time, centred on active learning, and focused on student outcomes" (p. 57). There is a need to design and implement ITE programmes in education faculties and departments that are fully appropriate to the WIL skills and realities that reflect the roles and competencies required of educators at schools today.

According to Groenewald (2007), three essential interrelated learning components contribute to work-based learning: 1) structured learning in the workplace, 2) the provision of appropriate on-the-job training/learning opportunities, and 3) the identification and provision of relevant off-the-job learning opportunities. Groenewald (2007) emphasizes the significance of a relationship between curriculum development based on the students' needs of their occupational field and appropriate placements in schools for WIL as part of the integrated programme. Cultivation of a supportive client base that would offer sufficient and appropriate workplacements is therefore necessary as this would maintain a continuous reciprocal advisory process and the organisation, co-ordination and assessment of WIL skills. These are considered to be the core components of co-operative education.

There is an increasing interest in accountability of curricula within HEIs to determine the degree to which students taking the courses are actually learning what the institutions expect them to learn. Fry, Ketteridge and Marshall (1999) refer to the debate about the meaning of quality and standards in HEIs which reflects different and sometimes conflicting expectations of what HEIs should provide and deliver. Killen (2000) confirms that in teacher education programmes, student teachers must be able to demonstrate their roles of being specialists in a particular learning area, subject or phase. The aim of the study was to investigate whether the one-year PGCE qualification at HEIs adequately develops the WIL knowledge and skills of student teachers. The objectives of the study were to ascertain the relationship between the theoretical knowledge provided by the PGCE curriculum and the development of WIL skills of student teachers in the schools and to determine the perceptions of school mentors of the PGCE to develop the WIL skills of student teachers. Therefore, the problem that was investigated in this study focused on the relationship between the theoretical knowledge provided by the PGCE curriculum at HEIs and the development of WIL skills of student teachers by their school mentors. The hypothesis for this study was: School mentors make a significant contribution to the development of the WIL skills of student teachers in the PGCE programme.

\section{Why Good Mentors Are Needed}

Good mentors are committed to the role of mentoring and they have an invitational attitude towards their student teachers. Such mentors are skilled at providing instructional support and are extremely effective in different interpersonal contexts. They exude hope and optimism and are models of being continuous learners (Rowley, 1999). School mentors are expected to shape, nurture and empower student teachers. This involves relationships, integrity and perpetual learning (Dungy, 2010). In her study on mentoring, Ligadu (2012) found that most mentees agreed that their positive development in their professional areas was due to both professional learning and psychological mentoring support provided by mentors in their roles as guides and advisors, and to the mentors' knowledge of content and pedagogical experience. Guidance and advice from the mentors on pedagogic matters, such as planning, instructional skills, knowledge and organisation of content and resources, and classroom management, were major contributors to this development. The mentors also gained from the programme in the development of insights into their own teaching and class management ability and their use of resources.

The role of being a mentor takes a great deal of time and expertise and makes a significant contribution to the development of student teachers. A salient characteristic of a good mentor is to demonstrate empathy and accept the mentee without making any preconceived judgements (Mahomed \& Singh, 2011; Rowley, 1999). As a school 
leader, the mentor shares with student teachers the vision of the school and aligns his or her professional goals with those of the school. Student teachers have access to a wealth of data to drive classroom instruction, made possible by their mentors. Mentors serve as catalysts for change and as visionaries who are never content with the status quo. As a learner, a mentor demonstrates lifelong learning and provides assistance to student teachers to be successful. Invaluable guidance is provided by the school mentors to hone the WIL skills of student teachers in order for them to develop into accomplished teachers (Harrison \& Killion, 2007).

Mentors focus on developing the strengths of individuals, and this works best when the student teachers being mentored by their assigned teachers in schools are aware that these mentors have a genuine concern for their development and success (Dungy, 2010). School mentors are expected to create an environment in which student teachers can be productive and able to excel. It is essential for each fledgling student teacher to be in an environment that nurtures fearless practice and discovery (Tomlinson, 2011). Therefore, the personal one-on-one mentoring is especially beneficial for student teachers to close the gap between the theory they are exposed to at HEIs and teaching practice at schools. Criticism that teacher education is too theoretical and that HEIs do not assume responsibility for the quality of their graduates is expressed in many countries, including South Africa (Stewart, 2011). This paper attempts to address this criticism by focusing on the interventions by school mentors in developing the WIL skills of student teachers in the PGCE programme.

Harrison and Killion (2007) stress the importance of school mentors in their roles as teacher leaders. As resource providers, mentors share their resources with the student teachers. They help student teachers implement effective teaching strategies. By being curriculum specialists, these mentors equip their student teachers with the know-how of the curriculum. They serve as classroom supporters by providing feedback to student teachers after observing their lessons. As learning facilitators, they create maximum opportunities for student teachers to develop their WIL skills. Student teachers must be aware that there's something to be learned from their school mentors and that it makes a difference when professional friendships increase their effectiveness rather than deplete it (Tomlinson, 2011). One of the challenges of teaching is that it implies educator involvement to do it well but demands that educators be observers of good practice (Squires, 2003). As reflective practitioners, student teachers need to monitor, observe and collect data on their own. Thereafter, they need to critically analyse the data. The next step in the process is the evaluation of the data so that decisions can be taken. Finally, the student teacher may have to revise classroom policies, plans and provision before the cycle is repeated. Student teachers are therefore constantly expected to reflect on their practice within the collegial environment created by the mentors at schools (Pollard, 2005).

\section{Developing the WIL Skills of Student Teachers}

The concept WIL is inherently experiential and developmental since students are given an opportunity to apply what they are learning as they are learning it in their occupational fields (Groenewald, 2007). This suggests that the concept WIL provides progressive experiences in integrating theory and practice. The integration and logistical co-ordination and assessment of the experiential and academic parts of curriculum development include partnerships between the student, the institution and their contextual work experiences (Stewart, 2011). WIL is utilised to describe the competencies that student teachers could develop to become effective teachers. In this study, WIL refers specifically to the competencies that PGCE student teachers are expected to acquire during the mentoring process when they are interns at their respective schools. Motivated school mentors are expected to provide PGCE student teachers with WIL skills of a high standard, particularly since these mentors are expected to be models of professionalism for the PGCE student teachers to emulate (Rowley, 1999; Dungy, 2010; Stewart, 2011).

The success of the PGCE programme is dependent upon the quality of the relationship between the HEIs, which train these student teachers, and the schools where the student teachers are mentored to acquire WIL skills (DoE, 2007). WIL is a form of education that integrates periods of academic study with periods of work experience in jobs related to the students' studies. It is offered at secondary, post-secondary and graduate levels by educational institutions in over 40 countries around the world (WACE, 2001). Educators of teachers who are concerned about the student teachers' acquisition of WIL must intervene at the programmatic level of curriculum implementation and be prepared to interrogate policy. The admission criteria for the PGCE in South Africa; namely, a degree with 
modules in approved school subjects, presuppose that the student has acquired adequate subject matter knowledge in at least two approved school subjects. It is expected that the PGCE candidate has also acquired a level of maturity associated with a graduate who has had exposure at an HEI and possibly acquired prior experience in a WIL environment.

One key notion about learning at work is that it is closely related to individuals' experience, reasoning, or logically thinking through their work experience and giving that experience meaning. This supports the development of curriculum frameworks for WIL as the bases for learning in workplaces that are not ad hoc or without structure. Curriculum frameworks for WIL are formalized and structured by the goals, activities and culture of the work practice (Gibson, Brodie, Sharpe, Wong, Deane \& Fraser, 2007). Orrell (2007) states that learning in workplacements needs to be deliberate and intentional, supported by induction of students and supervisors and the imaginative development of appropriate assessments to ensure the maintenance of high standards and adequate duty of care. Reflection and debriefing on the work by all parties is required to achieve these standards, as well as systematic evaluations for monitoring the quality of learning outcomes. Kolb's Experiential Learning Model provides a good description of the co-operative learning cycle as a four-stage cycle (Eames \& Cates, 2007). In the case of PGCE student teachers, they can commence with concrete experiences through academic coursework. This is followed by observation and reflection upon their experiences at the schools and when they return to the HEIs, student teachers will then be given assignments linked to observation and reflection while on the job. As a result of the experiences and reflections, the student teachers will be able to form concepts and generalizations that they will test in subsequent experiences.

Shulman (2004) asserts that in all professional preparations, there is some conception of a supervised clinical experience. Gibson et al. (2007) envisage WIL as an example of experiential learning. The experience of work is seen as an opportunity for student teachers to gain and apply knowledge, skills and attitudes, and values in authentic contexts in schools. There is a growing tendency internationally to refer to WIL in order to give a new meaning to the notion of co-operative education (Groenewald, 2007). Gitywa (2001) states that the practicum refers to that body of professional experience during which the student applies, tests and reconstructs the theory which is evolving and during which s/he further develops her/his own competence as a teacher. Excellent core knowledge, instructional strategies, content pedagogy and classroom management are all essential WIL skills to successful teaching that govern how the student teacher employs those skills inculcated by their mentors (Stewart, 2011; Scherer, 1998).

The challenge facing the student teachers is that they have to create a balance between the academic demands made upon them by the HEIs and the need for simultaneously maintaining the ongoing supportive roles with their school mentors (Stewart, 2011; Tomlinson, 2011). As pointed out by Smith, Wilson and Corbett (2009, p. 20), professional learning communities are a growing forum for teacher learning. The opportunity to share ideas and reflect on teaching practice makes these communities attractive to develop the WIL skills of student teachers. In undertaking WIL, students apply and refine their current knowledge and skills and learn new knowledge and skills, as well as apply, reflect on and review their experience as part of assessment. Positive outcomes must be carefully developed and worked toward actively by motivating participants, whilst consciously avoiding known difficulties (Gibson et al., 2007). Therefore, school mentors are required to assume a leading role to develop the WIL skills of their protégés to excel in teaching in terms of (Mahomed \& Singh, 2011; Abiddin \& Hassan, 2012; Singh, 2010; Ligadu, 2012; Johnson, 2007; Jonson, 2008):

1. Making choices regarding the instructional strategies to teach the contents

2. Developing their time management skills

3. Providing for individualization and differentiation within a heterogeneous class setting

4. Integrating media meaningfully in order to improve the comprehension of subject matter

5. Developing their understanding of psychological issues on how pupils learn

6. Developing effective classroom management skills

7. $\quad$ Using technology appropriately to foster self-regulated learning

8. Using student assessment data to reflect on and evaluate student learning and instructional practice

9. Revising instruction in response to evaluative feedback 
10. Establishing positive cooperative relationships with colleagues, administrators, parents and other community members

11. Using collegial teaming approaches to exchange professional materials and ideas with colleagues

\section{RESEARCH DESIGN}

The quantitative research method was used in this study. The target population comprised school mentors for PGCE students in the Nelson Mandela Metropole, Port Elizabeth, South Africa. Gorard (2001) refers to convenience sampling as a form of non-probability sampling which is composed of those cases chosen only because they are easily available. The mentors were therefore selected on the basis of their accessibility and availability. Eighteen high schools in Port Elizabeth and two high schools in Uitenhage provided the sites for this study. The questionnaire used in this study was based on Danielson's rubric (Danielson, 1996) on teacher competencies. Copyright permission was granted by Danielson to use the internationally valid domains and elements she identified which reflect the competencies that teachers are expected to master (see Table 1). The four domains and elements in each domain identified by Danielson guided the design of the questionnaire. The domains, sub-domains and elements identified by Danielson overlapped with the roles for educators as identified by the DoE (DoE, 2007). The questionnaire was therefore divided into four sections, depicting the WIL skills of teachers as follows: Domain 1 Preparation and planning, Domain 2 - The classroom environment, Domain 3 - Instruction, and Domain 4 Professional responsibilities.

Table 1: Cronbach's Alpha and the Mentors' Rating of their Protégés

\begin{tabular}{|c|c|c|c|}
\hline Domains and Elements in Sub-Domains & Sub-Domain & Cronbach's Alpha & Mentors' Rating \% \\
\hline \multicolumn{4}{|l|}{ Domain 1: Preparation \& Planning } \\
\hline Knowledge of content & 1 (a) & .89 & 73 \\
\hline Knowledge of learners & $1(\mathrm{~b})$ & .93 & 66 \\
\hline Selection \& implementation of goals & $1(\mathrm{c})$ & .92 & 70 \\
\hline Awareness of \& access to resources & $1(\mathrm{~d})$ & .92 & 71 \\
\hline Lesson structure \& learning activities & $1(\mathrm{e})$ & .91 & 71 \\
\hline Assessment & $1(\mathrm{f})$ & .89 & 69 \\
\hline \multicolumn{4}{|l|}{ Domain 2: Classroom Environment } \\
\hline Teacher \& learner interactions & $2(\mathrm{a})$ & .90 & 79 \\
\hline Learner expectations \& pride in work & $2(\mathrm{~b})$ & .92 & 74 \\
\hline Classroom management & $2(\mathrm{c})$ & .93 & 68 \\
\hline Monitoring of learner behaviour & $2(\mathrm{~d})$ & .89 & 68 \\
\hline Safety \& use of physical resources & $2(\mathrm{e})$ & .84 & 75 \\
\hline \multicolumn{4}{|l|}{ Domain 3: Instruction } \\
\hline Language proficiency & 3 (a) & .86 & 76 \\
\hline Questioning \& discussion techniques & $3(\mathrm{~b})$ & .88 & 72 \\
\hline Content disclosure & $3(\mathrm{c})$ & .92 & 71 \\
\hline Feedback & $3(\mathrm{~d})$ & .93 & 70 \\
\hline Lesson adjustment & $3(\mathrm{e})$ & .85 & 66 \\
\hline \multicolumn{4}{|l|}{ Domain 4: Professional Responsibilities } \\
\hline Reflection on teaching & $4(\mathrm{a})$ & .89 & 66 \\
\hline Administrative skills & $4(\mathrm{~b})$ & .94 & 65 \\
\hline Interaction with parents \& families & $4(\mathrm{c})$ & .95 & 53 \\
\hline Collegiality \& community service & $4(\mathrm{~d})$ & .90 & 70 \\
\hline Professional development & $4(\mathrm{e})$ & .86 & 71 \\
\hline
\end{tabular}

Allowance was made on the questionnaire for any additional comments which respondents might have wanted to include. Questions were grouped according to each of the elements within a sub-domain. The components of the elements therefore ensured that respondents were guided by the focus of the questions. Each element within a sub-domain was rated by the respondents on a five-point Likert-type scale. The respondents were guided with the rating where $1=$ poor, $3=$ average and $5=$ excellent. Thereafter, the respondents gave an overall rating out of ten for the particular sub-domain. The distribution of the items per domain for the school mentor questionnaire was as follows: Domain 1 - 55 items, Domain 2 - 31 items, Domain 3 - 34 items, and Domain 4 - 32 items. Twenty-eight 
questionnaires were completed by the school mentors. The statistical analysis of the data was done by a qualified statistician in the Statistical Unit at the Nelson Mandela Metropolitan University, Port Elizabeth, South Africa.

\section{Reliability of the Questionnaires}

The internal reliability for each of the sub-domains was calculated by using Cronbach's coefficient alpha. Cronbach's alpha is a coefficient of reliability or internal consistency. A high value, close to 1 , means that there is high internal reliability of the construct. This means that the items are highly correlated and measure the same construct to a high degree. The higher the score, the more reliable the generated scale is. The alpha values for the items in the questionnaires in this study, as indicated in Table 1 , ranged from 0.84 to 0.95 , which is an indicator of the measurement of the same construct to a high degree. These high values indicate that all the sub-domains have high internal reliability. It can therefore be deduced that the items were a consistent measure and that the four domains; namely, preparation and planning, classroom environment, instruction, and professional responsibilities, which indicate the WIL skills crucial for teachers, were also consistent.

\section{Validity}

The items on the questionnaire have face validity which, according to Struwig and Stead (2001), refers to whether the items of the test appear to measure what the test purports or claims to measure. All the items on the questionnaire are linked to WIL skills for educators and the WIL skills overlap with the competencies that are identified in the seven roles for educators. In addition, Danielson's research instrument, which was adapted for the questionnaires, has already been proven to be effective in regard to content validity. The items therefore also have content validity which is described by Struwig and Stead (2001) as the extent to which the items reflect the theoretical content domain of the construct being measured.

\section{Ethics}

Creswell (2005) identified the following ethical issues that must be considered in the research process respecting the rights of participants, honouring research sites, and reporting research fully and honestly. The rights of those who participated in the study were respected by providing them with the aim and objectives of the study and highlighting the relevance of the results of the study. The school mentors were also given a consent form which emphasised that their participation was voluntary and that there were no risks involved. Furthermore, they were informed that they had the right to refuse to participate or withdraw at any time during the study. They were assured of anonymity and their confidentiality was guaranteed. Their identities were protected by assigning numbers to the completed questionnaires.

\section{DISCUSSION OF FINDINGS}

The school mentors' rating of the PGCE student teachers per sub-domain is presented in Table 1. These are the overall ratings out of ten on the questionnaire, expressed as a percentage for each sub-domain. The ratings are therefore not a percentage of the respondents, but an average rating per sub-domain.

\section{Domain 1: Preparation and Planning}

Domain 1 consists of six sub-domains. Each sub-domain is further grouped into elements. The elements are indicative of the core competencies relating to preparation and planning that PGCE student teachers are expected to develop in WIL environments. In sub-domain 1(a), the focus was on knowledge of content and content-related pedagogy. The rating of $73 \%$ from the mentors is as a result of the mentors' observations of the benefits of the subject content knowledge that the student teachers have acquired in their undergraduate degrees prior to registering for the PGCE. Bourdillon and Storey (2002) refer to the impact of the mastery of subject content knowledge on the teaching of beginning teachers. It reflects their depth of subject knowledge and their ability to help learners understand the language and organizing of concepts in their subjects. Sub-domain 1(b) focused on the PGCE student teachers' knowledge of learners. In this sub-domain, the rating of school mentors was $66 \%$. The knowledge that student teachers have of learners could be ascribed to the maturity of the PGCE students and their exposure to many individuals in a number of varied occupations prior to registering for the PGCE. 
Mentors gave the student teachers a rating of $70 \%$ in sub-domain $1(\mathrm{c})$. The mentor rating of $71 \%$ for the PGCE students in sub-domain 1(d), which refers to teaching resources, is indicative of the students' capacity to access resources. In sub-domain 1(e), the mentor rating was $71 \%$ as well, which suggests that the standard of lesson planning, content selection, selection of resources for teaching, and time management are WIL skills that the PGCE student teachers coped with adequately. This suggests that the lesson planning done by the student teachers satisfied the criteria for lesson planning in the WIL environment. The mentor rating of $69 \%$ for sub-domain 1(f), which relates to assessment, shows that the student teachers have clarity about formative and summative assessment and about the significance of providing learners with feedback.

The findings of this study confirm that the student teachers under the tutorship of their mentors:

- $\quad$ Are well prepared in their major teaching field of study

- $\quad$ Demonstrate mastery of the contents of the subjects they teach

- Know how to plan lessons showing appropriate learner objectives and teaching procedures

- $\quad$ Select appropriate content, materials, and media/technology to account for individual differences among learners

- $\quad$ Plan assessments that are well aligned with learner objectives

- $\quad$ Demonstrate knowledge of child development and how it relates to learning

- Show awareness of psychological factors affecting learning, such as readiness, motivation, interest, success and reinforcement

- $\quad$ Integrate academic content within and across content areas

- $\quad$ Understand the importance of personal factors in the learner, such as self-image

- $\quad$ Are able to bridge the gap between theory and practice in order to develop their WIL skills

\section{Domain 2: The Classroom Environment}

Domain 2 consists of five sub-domains. Each sub-domain is further grouped into elements. The elements are indicative of the core competencies linked to WIL and the classroom environment. In sub-domain 2(a), with specific reference to the two elements; namely, Teacher Interaction with Learners and Learner Interactions, a rating of $79 \%$ was received from the school mentors. The school mentors' rating was $74 \%$ in sub-domain 2 (b) where the focus was on motivating the learners to take pride in their work and achievements. This perception of the school mentors could be ascribed to the student teachers' focus on the disclosure of subject specific content to ensure curriculum coverage. With regard to sub-domain 2(c), where the focus was on coping with group work and the management of instructional time and transitions, the school mentors gave the student teachers a rating of $68 \%$. In sub-domain 2(d), the focus was on the behaviour of learners. The school-based mentors gave the student teachers a rating of $68 \%$. In sub-domain $2(\mathrm{e})$, which is linked to safety and classroom arrangement, the mentors' rating of the students was $75 \%$.

These findings clearly illustrate the student teachers ability to:

- $\quad$ Provide a learning environment that is organized, stimulating and positive

- $\quad$ Communicate enthusiasm and demonstrate warmth and friendliness

- $\quad$ Use grammar correctly and express thoughts well

- $\quad$ Express positive expectations for all students

- $\quad$ Provide learners with opportunities for participating in the lessons

- $\quad$ Engender student interest and maintain learner involvement throughout the lesson

- $\quad$ Attend to the physical classroom environment

- Demonstrate respect for students and fosters mutual respect among students

In addition, their acquired WIL skills of classroom management indicated that they were capable of:

- $\quad$ Handling materials and routine tasks to promote engagement in class activities

- $\quad$ Setting clear expectations for behaviour and using praise effectively 
- $\quad$ Having a clear system for grading, handing in, and checking of students' work

- $\quad$ Letting students assume independent responsibility

- $\quad$ Stressing and reinforcing positive, desirable behaviour amongst their students

- $\quad$ Using effective, appropriate actions for major misbehaviour and dealing with serious inattention

- $\quad$ Valuing and supporting student diversity and addressing individual needs

\section{Domain 3: Instruction}

Domain 3 consists of five sub-domains. Each sub-domain is further grouped into elements. The elements are indicative of the core competencies linked to WIL and the classroom environment. In sub-domain 3(a), the competence to be mastered is language proficiency. In this WIL skill, the mentors' rating was $76 \%$, which strongly suggests that the student teachers developed sufficient cognitive academic language proficiency and interpersonal communication skills. Sub-domain 3(b) looked specifically at the capacity of student teachers to make use of questioning and discussion techniques, whilst simultaneously engaging all learners. The mentor rating of $72 \%$ indicates that students are confident about their capacity for this sub-domain.

In terms of the WIL skills in sub-domain 3(c) linked to the disclosure of content during instruction, the pacing of lessons and the utilization of resources, the school-based mentors rated the students $71 \%$. The WIL competencies, such as disclosing content and using resources, can be planned in advance. Pacing lessons, however, requires ongoing practice. The rating by their mentors suggests that the student teachers are coping well with the competencies in this sub-domain. The rating of $70 \%$ by mentors of the student teachers with regard to feedback, which was the focus of sub-domain 3(d), is indicative of the student teachers' capacity to cope successfully with assessment in the WIL environment during instruction. Sub-domain 3(e) highlights the student teachers' capacity to respond spontaneously, since this sub-domain looks at the student teachers' capacity to adjust lessons using an extensive repertoire of strategies, and to assist learners whilst enhancing teaching. In this regard, the mentors' rating of the students was $66 \%$. The mentors' lower rating of the PGCE student teachers in sub-domain 3(e) suggests that the PGCE student teachers were sometimes seen to experience difficulties with spontaneity when dealing with unexpected events during teaching.

In the implementation of instruction, the findings from this study confirm that student teachers acquired WIL skills to use instructional methods and materials appropriate to the planned objectives and learners' needs; ask clear, thought-provoking questions and use responses and questions from learners in teaching; use appropriate instructional strategies based on diverse student needs and assessment data; use available technology to implement instruction to facilitate student learning; and set clear expectations, directions and explanations related to lesson contents. The student teachers also developed their abilities to assess learning in relation to stated objectives through observation, performance, and formal assessment; and used this assessment data for diagnostic and remedial purposes. They provided meaningful feedback and were able to analyse and use assessment data for diagnostic purposes to promote student learning.

\section{Domain 4: Professional Responsibilities}

Domain 4 consists of six sub-domains. Each sub-domain is further grouped into elements. The elements are indicative of the core competencies linked to WIL and the classroom environment. Sub-domain 4(a) refers specifically to the student teachers' capacity to reflect on practice. The mentor rating of $66 \%$ for students suggests that this is a WIL skill that requires more attention in the HEIs. The capacity of student teachers to cope with administrative issues, particularly with the recording of learner progress as indicated in sub-domain 4(b), was rated low by school mentors at $65 \%$. Once again, there is a need for the HEIs to give attention to the development of WIL skills linked to record-keeping and related administrative tasks in the schools.

In sub-domain 4(c) professional responsibilities, with specific reference to the three elements; namely, information about the instructional programme, information about individual students/learners, and engagement of families in the instructional programme, received the lowest rating of 53\% from the school mentors. The possibility exists that student teachers were not afforded opportunities to engage with parents informally at school functions or formally in terms of discussions about learners' progress, whether positive or negative. The following responses 
from school mentors to the last item on the questionnaire, which was open-ended, suggests that the HEIs, when collaborating with the placement schools, need to emphasise the need for student teachers to be exposed to learners' parents on an ongoing basis under the guidance of the school mentors:

- In high school the communication with parents/family is only through the report at the end of the term and at parent/teacher functions.

- $\quad$ Student teachers are not expected to liaise with parents. This is conducted through the Subject Head or through the Grade Head, according to school procedure.

Aspects such as collegiality and participation in school projects, which are the WIL skills in sub-domain 4(d), received a rating of 70\%, suggesting that the mentors were positive about the student teachers' development of collegial and leadership skills.

The rating by school-based mentors $(71 \%)$ in sub-domain $4(\mathrm{e})$, with regard to the student teachers' enhancement of content knowledge, coupled with pedagogic skills, affirms the research related to the strengths that PGCE student teachers have as a result of their content knowledge acquisition during their undergraduate degrees. Finally, sub-domain 4(f), which describes the student teachers' capacity to be of service to learners and to participate in decision-making, was seen as an area that needs some development since the school mentors' rating of student teachers was only $68 \%$. Evidently, the findings indicate that school mentors develop the student teachers' WIL skills to follow school policies and procedures and demonstrate ethical behaviour, prepare reports accurately and promptly, and to handle routine clerical duties, participate in professional growth activities related to growth areas and school needs, and report progress through reports, learner feedback, and parent conferences.

\section{Correlation between Elements per Domain}

Table 2 reflects the Pearson product-moment correlation coefficients for the six elements of Domain 1 for the mentors' data.

Table 2: Domain 1

\begin{tabular}{|c|c|c|c|c|c|c|}
\hline \multicolumn{7}{|c|}{$\begin{array}{c}\text { Group }=\text { Mentor } \\
\text { Correlations: Marked Correlations Are Significant At } \mathrm{P}<.05000 \\
\mathrm{~N}=23 \text { (Casewise Deletion Of Missing Data) }\end{array}$} \\
\hline Variable & Dom1a & Dom1b & Dom1c & Dom1d & Dom1e & Dom1f \\
\hline Dom1a & 1.00 & 0.88 & 0.88 & 0.64 & 0.76 & 0.81 \\
\hline Dom1b & 0.88 & 1.00 & 0.81 & 0.61 & 0.79 & 0.84 \\
\hline Dom1c & 0.88 & 0.81 & 1.00 & 0.76 & 0.79 & 0.89 \\
\hline Dom1d & 0.64 & 0.61 & 0.76 & 1.00 & 0.72 & 0.80 \\
\hline Dom1e & 0.76 & 0.79 & 0.79 & 0.72 & 1.00 & 0.81 \\
\hline Dom1f & 0.81 & 0.84 & 0.89 & 0.80 & 0.81 & 1.00 \\
\hline
\end{tabular}

The coefficients are all positive and very high, as well as statistically significant at the $5 \%$ level. This means that the mentors rated the student teachers consistently on the six elements. For example, the Pearson correlation between 1(a) (knowledge of content) and 1(c) (selection and implementation of goals) is 0.88 with a highly significant p-value of less than 0.05 . This indicates that a significant relationship exists between 1(a) and 1(c) as rated by the mentors.

Table 3 shows the Pearson product-moment correlation coefficients among the five elements of Domain 2 for the mentors' data. The mentors again rated the student teachers consistently high on the six elements. For example, the Pearson correlation between 2(c) (group work and management of instructional time and transitions) and 2(d) (behaviour of learners) is 0.85 with a highly significant p-value of less than 0.05 . This indicates that a significant relationship exists between 2 (c) and 2(d) as rated by the mentors. 
Table 3: Domain 2

Group = Mentor

Correlations: Marked Correlations Are Significant At $\mathrm{P}<.05000$

$\mathrm{N}=23$ (Casewise Deletion Of Missing Data)

\begin{tabular}{|l|c|c|c|c|c|}
\hline Variable & Dom2a & Dom2b & Dom2c & Dom2d & Dom2e \\
\hline Dom2a & 1.00 & 0.81 & 0.62 & 0.57 & 0.64 \\
\hline Dom2b & 0.81 & 1.00 & 0.78 & 0.79 & 0.66 \\
\hline Dom2c & 0.62 & 0.78 & 1.00 & 0.85 & 0.80 \\
\hline Dom2d & 0.57 & 0.79 & 0.85 & 1.00 & 0.75 \\
\hline Dom2e & 0.64 & 0.66 & 0.80 & 0.75 & 1.00 \\
\hline
\end{tabular}

Table 4 shows the Pearson product-moment correlation coefficients among the five elements of Domain 3 for the mentors' data. The mentors rated the student teachers consistently high on the five elements. For example, the Pearson correlation between 3(a) (language proficiency) and 3(c) (content disclosure, lesson pacing and resources) is 0.88 with a highly significant $\mathrm{p}$-value of less than 0.05 . This indicates that a significant relationship exists between 3(a) and 3(c) as rated by the mentors.

Table 4: Domain 3

Group = Mentor

\begin{tabular}{|c|c|c|c|c|c|}
\hline \multicolumn{7}{|c|}{$\begin{array}{c}\text { Correlations: Marked Correlations Are Significant At P }<.05000 \\
\text { N=23 (Casewise Deletion Of Missing Data) }\end{array}$} \\
\hline Variable & Dom3a & Dom3b & Dom3c & Dom3d & Dom3e \\
\hline Dom3a & 1.00 & 0.65 & 0.88 & 0.79 & 0.72 \\
\hline Dom3b & 0.65 & 1.00 & 0.67 & 0.65 & 0.75 \\
\hline Dom3c & 0.88 & 0.67 & 1.00 & 0.84 & 0.78 \\
\hline Dom3d & 0.79 & 0.65 & 0.84 & 1.00 & 0.74 \\
\hline Dom3e & 0.72 & 0.75 & 0.78 & 0.74 & 1.00 \\
\hline
\end{tabular}

Table 5 shows the Pearson product-moment correlation coefficients among the six elements in Domain 4 for the mentors' data. The mentors rated the student teachers consistently high on the six elements. For example, the Pearson correlation between 4(d) (collegiality and participation in school and district projects) and 4(f) (service to learners and participation in decision-making) is 0.91 with a highly significant p-value of less than 0.05 . This indicates that a significant relationship exists between $4(d)$ and 4(f) as rated by the mentors.

Table 5: Domain 4

Group $=$ Mentor

\begin{tabular}{|c|c|c|c|c|c|c|}
\hline \multicolumn{7}{|c|}{$\begin{array}{c}\text { Group }=\text { Mentor } \\
\text { Correlations: Marked Correlations Are Significant At } \mathrm{P}<.05000 \\
\mathrm{~N}=23 \text { (Casewise Deletion Of Missing Data) }\end{array}$} \\
\hline Variable & Dom4a & Dom4b & Dom4c & Dom4d & Dom4e & Dom4f \\
\hline Dom4a & 1.00 & 0.83 & 0.62 & 0.86 & 0.70 & 0.85 \\
\hline Dom4b & 0.83 & 1.00 & 0.69 & 0.85 & 0.67 & 0.82 \\
\hline Dom4c & 0.62 & 0.69 & 1.00 & 0.70 & 0.62 & 0.77 \\
\hline Dom4d & 0.86 & 0.85 & 0.70 & 1.00 & 0.81 & 0.91 \\
\hline Dom4e & 0.70 & 0.67 & 0.62 & 0.81 & 1.00 & 0.85 \\
\hline Dom4f & 0.85 & 0.82 & 0.77 & 0.91 & 0.85 & 1.00 \\
\hline
\end{tabular}

\section{Value of Mentoring: A Sweat Analysis}

The findings of this study clearly indicate that the PGCE adequately develops the WIL skills of student teachers. These findings clearly evoke the value of mentoring which can be further analysed using the SWEAT achievement model (see Figure 1) (Singh, 2010). 


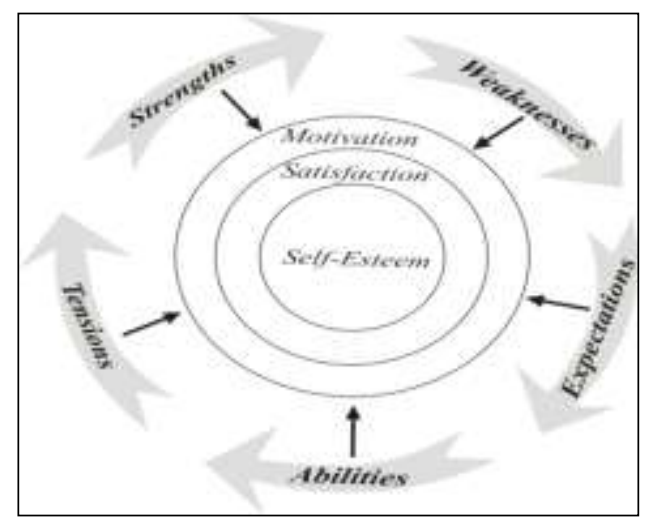

Figure 1: SWEAT Achievement Model

\section{Strengths}

WIL skills, which provide opportunities for students to apply theoretical knowledge, develop and consolidate instructional skills, reflect on practice and develop an understanding of the relevant profession or related sectors, are essential to providing real-world experiences. It is not axiomatic that anyone can assume the role of mentors without training. Commitment is a significant trait of being a good mentor and, as Rowley (1999) succinctly points out, committed mentors show up for, and stay on, the job. Such mentors understand that persistence is as important in mentoring as it is in classroom teaching seeing that mentoring can be a challenging endeavour requiring significant investments of time and energy. In this study, it was evident that mentors were well-trained in order to meet the WIL needs of their protégés.

\section{Weaknesses}

It is not always obvious that mentors will provide quality instructional support to their protégés. Many mentor teachers stop short of providing quality instructional support because the school culture does not encourage teachers to observe one another in their classrooms (Rowley,1999). Lack of collegial teaming can impact negatively on the mentor-mentee relationship. Maximum opportunities must be created for mentors to impart their WIL skills in their classrooms. Simply having staffroom conversations initiated by mentors will not suffice since such preconferences must be backed up with quality classroom observations and critical postconferences that lead ultimately to valuable clinical support of mentees. As aptly pointed out by Rowley (1999):

All beginning teachers are not created equal, nor are all mentor teachers. This simple fact, when overlooked or ignored by a mentor teacher, often leads to relationship difficulties and diminished support for the beginning teacher.

There are other shortcomings that have been also pointed out in this study that the HEIs need to address in the PGCE programme. There is a need to be aware of the current realities in the schools regarding constant curriculum changes and HEIs must take cognisance of these realities when recurriculating ITE programmes. The question that frequently arises is whether teachers have the professional competencies to manage curriculum change in their own classrooms and concomitantly serve as mentors to student teachers. HEIs and schools need to work closely in partnership to bridge this curriculum gap.

\section{Expectations}

If the appropriateness of ITE training programmes to the reality of today's classrooms is the focus of HEIs, then WIL has to be a significant component of the ITE teacher training curriculum. Professional learning support to develop the skills of teaching forms a major component of mentoring in schools. Teachers are currently facing many challenges, which include managing a diversity of learners from varying backgrounds and with special needs (Ligadu, 2012; Hargreaves \& Fullan, 2000). Without their mentors' support, student teachers will experience 
difficulty adapting what they learned in the HEIs to their teaching in schools (Jonson, 2008; McIntyre \& Hagger, 1996). To meet the expectations of their protégés, teacher mentors need to be competent in subject matter, as well as possess the relevant skills and knowledge for providing quality education in their classrooms (Ligadu, 2012; Singh, 2013a).

\section{Abilities}

Mentors must serve as role models to their mentees. The success of the mentors in this study alluded clearly to their ability of being suitably qualified in their field of specialization and developing the WIL skills of the student teachers under their pastoral care. A nurturing environment that meets personal and emotional needs can strengthen the mentees' WIL skills and empower them to be better able to meet their daily teaching demands and challenges (Ligadu, 2012; Kilburg, 2007; McIntyre \& Hagger, 1996).

\section{Tensions}

It is inappropriate to regard beginning teachers as finished products, assuming that they are capable of fulfilling their teaching obligations without any anxiety, tensions and difficulties (Singh, 2013b). In his studies on tobephobia, Singh (2013b) found that when teachers lack professional competencies to teach what is expected of them, they would experience fear of failure. Student teachers find this a traumatic experience, especially those with very little teaching experience (Ismail, 2001; Ligadu, 2012). Fortunately, in this study, student teachers were required to demonstrate their competencies in terms of Danielson's rubric (Danielson, 1996). They were not imposed with additional tasks that are usually executed by experienced teachers. As a result, the mentees in this study were not subjected to undue tensions in developing their WIL skills.

\section{Motivation}

A good mentor recognises the power of accepting the beginning teacher as a developing person and professional (Rowley, 1999). Hence, it is imperative that schools and HEIs ensure that mentors continue their own professional growth and development in order to motivate them to excel in developing the WIL skills of student teachers. In this study, caring, experienced and suitably qualified mentors were appointed. This is essential for mentoring to be successful because good "mentor teachers capitalize on opportunities to affirm the human potential of their mentees" (Rowley, 1999, p. 21). Teacher mentors, who work along with their protégés effectively and efficiently, have been found, even in this study, to be those who interact directly with their mentees in facilitating and supervising instructional processes (Ligadu, 2012). These mentors also motivate their protégés by constantly lending them professional and emotional support by incorporating the humanist element into this relationship (Wang \& Odell, 2002). This adds to the success of the mentoring process, especially for the mentees who can discover an array of new responsibilities during the practicum (Ligadu, 2012; Mahomed \& Singh, 2011).

\section{Satisfaction}

If student teachers and administrators value mentoring highly and take it seriously, mentoring will attract caring and committed teachers who recognize the complex and challenging nature of classroom teaching. It will attract mentor teachers who demonstrate their hope and optimism for the future by their willingness to help a student teacher discover the same joys and satisfactions that they have found in their own career. It is therefore essential to take the necessary precautions to avoid using veteran teachers who have lost their positive outlook in the teaching profession (Rowley, 1999). Mentoring must attract caring and highly committed teachers who recognise the complex and challenging nature of classroom teaching. Rowley (1999) avers that it "will attract teachers who demonstrate their hope and optimism for the future by their willingness to help a new teacher discover the same joys and satisfactions that they have found in their own career" (p. 21). Parker, as quoted by Scherer (1998), draws our attention on the complexity of becoming a teacher:

If we want to grow in our practice, we have two primary places to go - to the inner ground from which good teaching comes and to the community of fellow teachers from whom we can learn about ourselves and our craft. The resources we need in order to grow as teachers are abundant within the community of colleagues. (p. 5) 


\section{Self-Esteem}

Developing the self-confidence and, consequently, the self-esteem of student teachers is a vital component of the mentoring process. Committed mentors have a distinguished way of bringing joy and self-esteem to their students by ensuring that they realise their hidden talents and their potential to succeed in the teaching profession (Prince, 2004). It is therefore imperative that mentees are provided psychological support, especially during the practicum where teaching is considered an emotional experience (Ligadu, 2012; Johnson, 2007; Tickle, 1991). Johnson (2007) affirms that consistent support creates a safe climate in which student teachers can take risks and do the work of developing personally and professionally. Such support is a necessity to simply reassure and guide beginning teachers, as well as to reduce their anxieties and frustrations, and their fear of failure; namely, tobephobia (Ligadu, 2012; Singh, 2013b). Hence, the psychological support provided by mentors to their protégés would assist in building their self-concept and self-esteem (Ligadu, 2012). In this study, the PGCE students were given adequate psychological support by their school mentors in order to develop their self-esteem.

\section{CONCLUSION}

The findings of this study clearly support the hypothesis that school mentors make a significant contribution to the development of the WIL skills of student teachers in the PGCE programme. Such commitment flows naturally from a resolute belief that mentors are capable of making a significant and positive impact on their protégés. The student teachers were able to develop their WIL skills by working collaboratively under the expert tutorship of their school mentors. This partnership between the school and the HEIs needs to be further strengthened in order to bridge the gap between theory and practice. More research needs to be done on how WIL for student teachers can facilitate a partnership between HEIs and schools in developing relevant curricula for student teachers to implement in practice.

\section{AUTHOR INFORMATION}

Prakash Singh is a professor of education at the Nelson Mandela Metropolitan University in Port Elizabeth, South Africa. He is currently a rated researcher by the National Research Foundation in South Africa, and is a former Senior Research Fulbright scholar. Professor Singh is the author of Innovative Strategies to Develop Better Schools and co-author of Principal Leadership. He has also published widely in peer-reviewed journals, focusing on collegial leadership, traditional bureaucratic management practices, organisational effectiveness, emotional intelligence, tobephobia, and self-regulated learning. Professor Singh has presented numerous papers at international conferences. E-mail: Prakash.Singh@nmmu.ac.za (Corresponding author)

Carmel Claire Mahomed is a lecturer in the faculty of education at the Nelson Mandela Metropolitan University. She is currently reading for a $\mathrm{PhD}$ focusing on mentoring in the work-integrated learning environment. Mrs Mahomed has published a book titled: Adequacy of Postgraduate Certificate In Education. She has also published articles and presented papers at conferences. E-mail: carmel.mahomed@nmmu.ac.za

\section{REFERENCES}

1. Abiddin, N.Z. \& Hassan, A. (2012). A review of effective mentoring practices for mentees' development. Journal of Studies in Education, 2(1): 72-89.

2. Bilesanmi, B. (2011). Mentoring: an emerging trend in the forefront of human resources management. IFE Psycholog 1A, 92-103.

3. Bourdillon, H., \& Storey, A. (2002). Aspects of teaching and learning in secondary schools. London: The Open University.

4. Chappuis, S., Chappuis, J. \& Stiggins, R. (2009). Supporting teacher learning teams. Educational Leadership, 66(5): 56-60.

5. Creswell, J. W. (2005). Educational research: planning, conducting and evaluating quantitative and qualitative research. New Jersey: Pearson Merrill Prentice Hall.

6. Danielson, C. (1996). Enhancing professional practice: a framework for teaching. Princeton: ASCD. 
7. Department of Education (DoE). (2007). The National Policy Framework for teacher education and development in South Africa. Government Gazette 29832. Pretoria: Government Printer.

8. Dungy, T. (2010). The mentor leader. Carol Stream, Illinois: Tyndale House.

9. Eames, C., \& Cates, C. (2007). Theories of learning in co-operative education. In R.K.Coll, \& C. Eames (Eds.), International handbook for co-operative education. Hamilton: Waikato Print.

10. Fry, H., Ketteridge, S. \& Marshall, S. (Eds). (1999). A handbook for teaching \& learning in higher education enhancing academic practice. London: Kogan.

11. Gibson, E., Brodie, S., Sharpe, D., Wong, E., Deane, E. \& Fraser, S. (2007). Towards the development of a work-integrated learning unit. Retrieved from: http://www.cfl.mq.edu.au/celebrate/pdf/papers/gibson1.pdf

12. Gitywa, M. (2001). The role of lecturers in the preparation of teachers for teaching practice. (Unpublished master's thesis). Port Elizabeth: University of Port Elizabeth.

13. Gorard, S. (2001). Quantitative methods in educational research: The role of numbers made easy. London: Continuum.

14. Groenewald, T. (2007). Towards a definition for co-operative education. In R.K.Coll, \& C. Eames (Eds.), International handbook for co-operative education. Hamilton: Waikato Print.

15. Hargreaves, A. \& Fullan, M. (2000). Mentoring in the new millennium. Theory into Practice, 39(1): 50-56.

16. Harrison, C. \& Killion, J. (2007). Ten roles for teacher leaders. Educational Leadership, 65(1): 74-77.

17. Ismail, N.B.H. (2001). The mentoring processes of primary ESL student teachers in Malaysia. Exeter, UK: University of Exeter.

18. Johnson, W.B. (2007). On being a mentor: A guide for higher education faculty. New Jersey: Routledge.

19. Jonson, K.F. (2008). Being an effective mentor: How to help beginning teachers succeed. California: Corwin.

20. Kilburg, G.M. (2007). Three mentoring team relationships and obstacles encountered: A school-based case study. Mentoring \& Tutoring, 15(3): 293-308.

21. Killen, R. (2000). Teaching strategies for Outcomes-based Education. Lansdowne: Juta \& Co Ltd.

22. Ligadu, P.C. (2012). The impact of the professional learning and psychological mentoring support for teacher trainees. Journal of Social Sciences, 8(3): 350-363.

23. Mahomed, C.C. \& Singh, P. (2011). Work-integrated learning skills: A comparison of teachers' perceptions about the PGCE with those of student teachers in the Nelson Mandela Metropole. Africa Education Review, 8(3): 504-528.

24. McIntyre, D. \& Hagger, H. (1996). Mentors in schools: Developing the profession of teaching. London: Fulton.

25. Orrell, J. (2007). Work-integrated learning programmes: Management and educational quality. Proceedings of the Australian Universities Quality Forum. Retrieved from: http://www.auqa.edu.au/auqf/2004/program/papers/Orrell.pdf-

26. Pollard, A. (2005). Reflective teaching. London: Continuum.

27. Prince, S.R. (2004). The magic of mentoring. Educational Leadership, 61(8): 84-86.

28. Rowley, S.B. (1999). The good mentor. Educational Leadership, 56(8): 20-22.

29. Scherer, M. (1998). The importance of being a colleague. Educational Leadership,55(5): 5.

30. Shulman, L.S. (2004). The wisdom of practice: Essays on teaching, learning, and learning to teach. San Francisco: Jossey-Bass.

31. Singh, P. (2010). Innovative strategies to develop better schools. Sydney, Australia: Common Ground.

32. Singh, P. (2013a). Accounting enrichment program for gifted high school pupils: Self-regulated learning strategies to develop our future business leaders. International Business \& Economics Research Journal, 12(1): 103-112.

33. Singh, P. (2013b). Fear abounds in the educational environment: Teachers' professional competencies in the management of knowledge. International Business \& Economics Research Journal, 12(6): 687-700.

34. Smith, D., Wilson, B. \& Corbett, D. (2009). Moving beyond talk. Educational Leadership 66(5): 20-25.

35. Squires, G. (2003). Trouble-shooting your teaching. London: Kogan Page.

36. Stewart, V. (2011). Raising teacher quality around the world. Educational Leadership, 68(4): 16-20.

37. Struwig, F.W. \& Stead, G.B. (2001). Planning, designing \& reporting research. Cape Town: Maskew Miller Longman (Pty) Ltd.

38. Tickle, L. (1991). New teachers and the emotions of learning teaching. Cambridge Journal of Education, 21(3): 319-329. 
39. Tomlinson, C.A. (2011). Notes from an accidental teacher. Educational Leadership, 68(4): 22-26.

40. Wang, J. \& Odell, S.J. (2002). Mentored learning to teach according to standards-based reform: A critical review. Review of Educational Research, 72(3): 481-546.

41. World Association for Co-operative Education (WACE), Inc. July 2001. Employers' guide to workintegrated learning. Retrieved from: http://www.waceinc.org/pdf/Abbreviated_Guide.pdf 
NOTES 